\title{
INTRODUCTION OF THE SYSTEM OF INTERDISCIPLINARY EDUCATION OF VSTU
}

\author{
Anna Vorotyntseva ${ }^{1}$, Lyudmila Komyshova ${ }^{2}$, Vadim Belousov ${ }^{3}$, Anton Akopyan ${ }^{4}$ \\ ${ }^{1}$ Candidate of Economics Sciences, Associate Professor, Voronezh State Technical University, \\ 20 years of October Street, 84, Voronezh, Russia, E-mail: allslavin@mail.ru \\ ${ }^{2}$ Senior teacher, Voronezh State Technical University, \\ 20 years of October Street, 84, Voronezh, Russia, E-mail: mila_kom@mail.ru \\ ${ }^{3}$ Candidate of Technical Sciences, Associate Professor, Voronezh State Technical University, \\ 20 years of October Street, 84, Voronezh, Russia, E-mail: vigasuvgtu@yandex.ru \\ ${ }^{4}$ Acting Dean of the Faculty of Culture and Education, Voronezh State Technical University, \\ 20 years of October Street, 84, Voronezh, Russia, E-mail: akop_antoxa@mail.ru
}

\begin{abstract}
This article presents the results of the development of the project "The System of Interdisciplinary Education in Universities", which successfully passed an online selection and was included in the top 600 leaders of the National track of the business program of the WorldSkills Kazan 2019 World Championship. Currently, the classical methods of training specialists do not provide an opportunity to bring the educational process to the real conditions of production in solving the problems of effective management of complex organizational and technical systems. The goal of any educational system is to ensure that the knowledge acquired by a specialist is consistent with the requirements of employers. Modern companies require specialists with a wide range of knowledge, able to work and make decisions in a team. The changes that have already begun to take place on the international labor market will directly affect all modern working professionals and current students. Therefore, the increased interest of students in interdisciplinary education is predicted everywhere, which will allow them to ensure their future and career growth
\end{abstract}

Keywords: higher education, interdisciplinary training, rigid and flexible competencies, competency-based approach

\section{INTRODUCTION}

Recently, the combination of the so-called "hard" and "flexible" competencies in an employee, the possession of teamwork skills, and knowledge not only in his highly specialized field have become particularly relevant. In other words, over time, knowledge and experience in only one narrow area will not be enough. Workers with knowledge in a number of related fields will be most in demand. In modern society, the traditional division into "humanities" and "techies" is gradually disappearing. Today it is no longer possible to work in the humanitarian sphere without an understanding of technology and the natural science picture of the world, and vice versa. We see an ever-increasing demand from employers for "team players." This leads to the fact that among students there is a growing interest in multidisciplinary education, which will allow them to ensure their future and career growth. 
Within the framework of the National Qualifications System, the project "System of Interdisciplinary Education in Universities" is one of the means to coordinate the demand for qualifications of employees from employers based on labor market requirements and the proposal of qualifications from the education and training system, solving the following tasks:

1. Creation of conditions for expanding the range of public-private partnership models.

2. Formation of centers of applied (professional) qualifications.

3. Introduction of new models of resource support and management of educational programs, including modular and network ones.

4. Creation of conditions for the construction and implementation of individual vocational education routes and support for the employment of persons with disabilities.

Having studied the national and foreign experience of this type of activity, we came to the conclusion that the goal of the project should be the formation of an effective system for the development and retention of talented youth through the modernization of the educational process in the university to preserve and increase the human capital of the region and the development of entrepreneurship with the simultaneous development of individual educational technology among students trajectories in creating innovative design solutions for real production as part of a temporary creative stake lens. To this end, it is proposed, within the framework of introducing an interdisciplinary education system at VSTU, to solve the problems:

1. Build a system for identifying key competencies of talented people and form youth communities in areas of interest and areas of activity,

2. To develop the innovative activities of universities in the training of personnel, to introduce innovative educational technologies in the educational process

3. Develop individual educational trajectories.

4. Develop interdisciplinary educational projects (IEP).

5. To form a system of planning, management and resource and organizational support of interdisciplinary educational projects.

6. To analyze and summarize domestic and foreign experience in the field of interdisciplinary educational technologies and their application in the educational process of the university.

7. To develop relations with external partners for the purpose of joint work in the field of development of interdisciplinary educational projects and technologies, the development of a system of professional mentoring.

8. Introduce an effective system for retaining talented youth through the formation and promotion of the Golden Personnel Fund, entrepreneurial design and support for project participants

\section{METHODOLOGY}

In the course of studying the labor market, it was found that when managing complex projects, many employers faced the problem of selecting employees who have competencies in related fields and are generally able to work in the structure of temporary creative teams, and with the development of automation tools, the line between engineering and managerial staff will be blurred more and more. executive level (technicians and highly skilled workers).

\section{DISCUSSION}

Thus, university graduates should have new qualities, namely:

- Willingness to work at the junction of specialties;

- The ability to work remotely and with a lot of information;

- Think creatively and creatively and have flexible skills (soft skills), etc.

All this will allow to achieve the following qualitative results:

- Unscrew the quality system of education,

- Make graduates more in demand on the labor market, 
Proceedings of SOCIOINT 2020- 7th International Conference on Education and Education of Social Sciences,

- Increase the motivation and prestige of higher education, including engineering and scientific and technical education,

- Learn how to interact with each other;

- Get a clear idea of their role in the implementation of the project as a whole.

In order to form a wide class of competences among students of various educational levels, regardless of university affiliation, it is proposed to introduce interdisciplinary training technology into the practice of preparing students, which will allow forming a wide class of competencies in accordance with the Federal State Educational Standard and additional competencies that support personal growth, stimulate research and innovation:

1. Methodology for the purposeful development and retention of talented young people of the region using the mechanism of mentoring (Clause 1.2.3. And Clause 2.3.1 of the University Culture Center)

2. Development of motivation, improving the quality and prestige of engineering and scientific and technical education (Clause 1.2.3. DCU)

3. Creating an updated database of analytical tests, techniques and technologies for identifying talents. (Clause 1.2.3. DCU)

4. The methodology of transition to individual educational trajectories using the mechanism of mentoring (paragraph 1.1.1 and paragraph 1.2.3. DCU)

5. Creation of information content "Center for the Development of Talented Youth" in the unified information space of the university (clauses 2.2.5. And 2.3.3. DCU)

6. Methods of escorting project participants on the way and after employment (clause 2.3.1 of DCU).

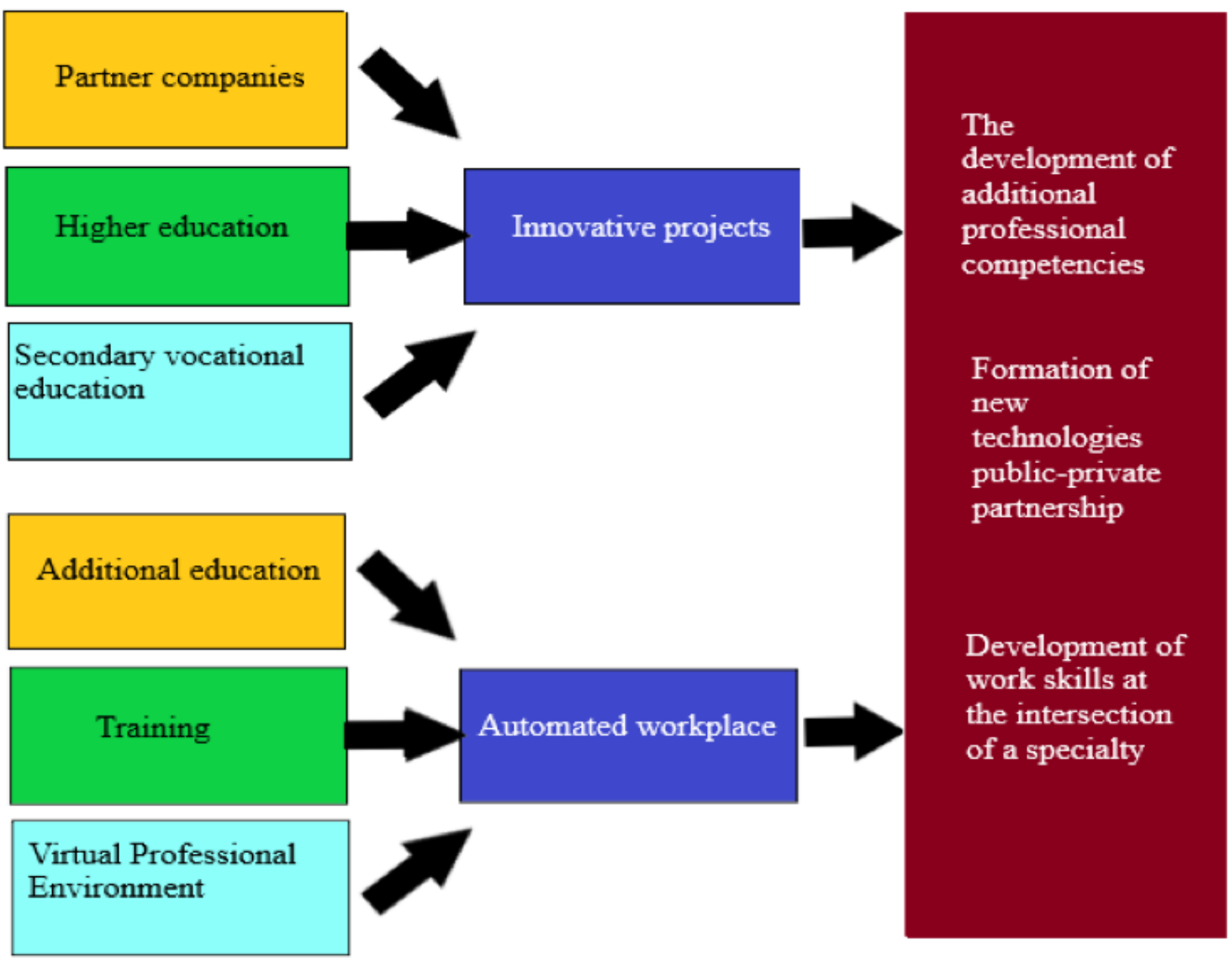

Fig. 1. The scheme of formation of additional competencies in the course of interdisciplinary training 
Figure 1 shows a diagram of the formation of additional competencies in the course of interdisciplinary training, which is a two-level structure that allows students of higher and secondary vocational education to receive additional competencies when solving innovative projects of partner enterprises, and for students with advanced training programs and additional education to receive them in the framework of virtual professional environment through the mechanisms of workstations.

To solve this goal, it is proposed to form temporary creative teams from among senior students of various specialties, which, under the guidance of tutors and tutors, will be involved in solving the problems of managing complex organizational and technical systems of specific enterprises on the basis of subjectoriented project activities. Based on the results of such activities, a comprehensive project is being formed aimed at solving problems of increasing production efficiency, which will be evaluated by employers and representatives of the university.

The innovative courses received during practical interdisciplinary training are the basis for the development of virtual enterprises with the possibility of modeling the problems of managing complex organizational and technical systems. To implement this approach, it is possible to create a set of automated workers, allowing students to immerse themselves in a virtual environment that simulates the work of the enterprise. The virtual environment is implemented as a system of computer simulators for specialists of various profiles, the main emphasis of which is placed on the interaction of these specialists in a joint analysis and decision-making in regular and non-staff production and design situations (Figure 2).

At the next stage of the project, it is planned to use the resources of the regional multifunctional center of applied competencies, and the partners in the project will be: V.A. Trapeznikova RAS (Moscow) and East Mediterranean University of the Republic of Cyprus.

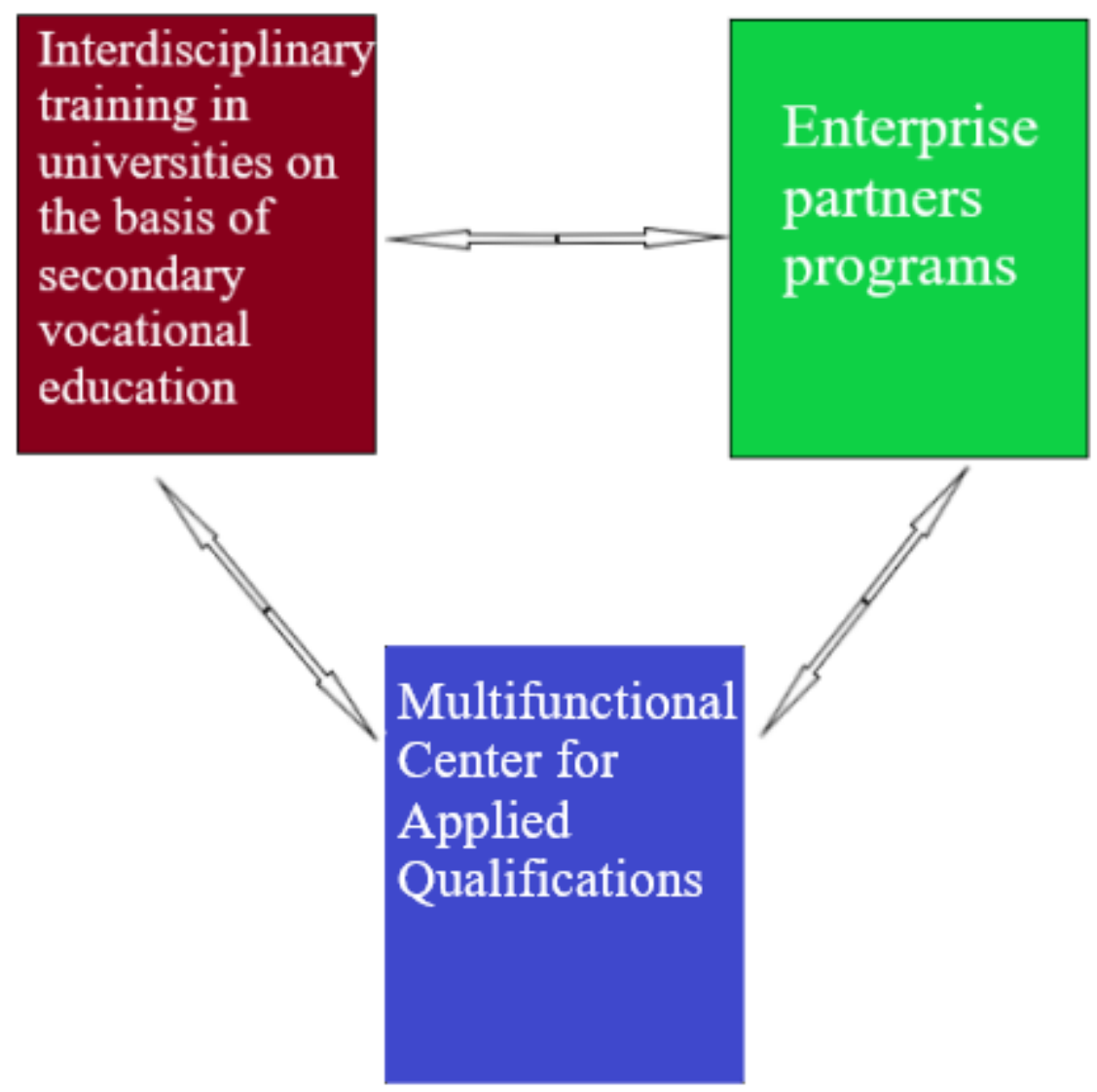

Fig. 2. MCA with the involvement of the IFC applied qualifications

\section{RESULTS}

Our experience in implementing interdisciplinary training projects lies in the successful conduct in November 2018 at the site of PJSC Voronezh Joint-Stock Aircraft-Building Society of a scientific and practical seminar "Management of high-tech production processes" in conjunction with the Moscow Aviation Institute through 
the mediation of GC ROSTECH and UAC. To solve the problems of the enterprise, students of four specialties were involved in four teams working in two workshops. Based on the results of work at the enterprise, with the help of tutors (engineering staff), practice-oriented projects were developed that were defended on the site of the VGTU business incubator before a commission of 8 enterprises and associations of Russia. According to experts, by 2030 about 140 new professions will appear in the world, most of which will be interdisciplinary. These include: the designer of the "smart home", the architect of the "energy-zero" houses, the gamemaker, the game practitioner, and many others.

\section{v. CONCLUSION}

Therefore, we believe that the implementation of this project will allow us to adapt our graduates to the requirements of the international labor market, and, therefore, increase the competitiveness of our education. For the domestic education system, vertical and horizontal integration of all levels of education will be achieved as part of the acquisition of applied qualifications [7].

\section{REFERENCE LIST}

Vorotyntseva A. V. (2019) / System Implementation of interdisciplinary education VGTU // Economics of the investment and construction complex and housing and utilities. № 2 (17). Pp. 89-95. (in Russian).

Komyshova L. N. (2013). Development of a methodological system of advanced professional retraining of managers and specialists of organizations // FES: Finance. Economics. No. 3. P. 48. (in Russian).

Maslikhova L. I., Petrenko V. R., Korshunova S. A. (2019) Achievements of technical education of the Voronezh region as a guarantee of successful development of the country and the region (rev. On the book: 110 years of technical education of the voronezh region: anniversary edition. Voronezh : VSTU publishing house, 2018. 240 p). Bulletin of the Voronezh state University. Series: Problems of higher education № 4. Pp. 114-117. (in Russian).

Ovsyannikov A.S. (2013). Mechanisms of the formation of the labor potential of the construction industry // Scientific Bulletin of the Voronezh State University of Architecture and Civil Engineering. Series: Economics and Entrepreneurship. No. 11. Pp. 13-17. (in Russian).

Semenov V.N. (2013). The formation of the innovative nature of the system of continuing professional education in construction // Socio-economic problems of the modern labor market. Materials of the International scientific-practical conference. Pp. 141-144. (in Russian).

Sergeeva S.I. (2015). Project activity as a means of implementing federal state educational standards // FES: Finance. Economics . No. 11. Pp. 17-18. (in Russian).

Uvarova S.S. (2018). Development of a mentoring mechanism at the university from the point of view of the project approach // FES: Finance. Economics .T. 15. No. 5. Pp. 24-29. (in Russian).

Uvarova S.S. (2018). Mentoring as a tool to improve the efficiency of training highly qualified specialists in construction // Economics and Entrepreneurship. No. 1 (90). Pp. 672-677. (in Russian). 